\title{
Low Ankle-Brachial Index is Associated with Microvascular Coronary Obstruction After Primary $\mathrm{PCl}$
}

This article was published in the following Dove Press journal: Vascular Health and Risk Management

\author{
Ahmed Abdel-Galeel (D) \\ Ahmed El-Zokaim ${ }^{2}$ \\ Hosam Hasan-Ali $\mathbb{D D}^{1}$ \\ Ahmed Ibrahim (D) ${ }^{3}$ \\ Ayman Ibrahim (iD ${ }^{2}$ \\ Ramadan Ghaleb ${ }^{2}$ \\ 'Cardiovascular Medicine Department, \\ Assiut University Heart Hospital, Assiut \\ University, Assiut, Egypt; ${ }^{2}$ Cardiology \\ Department, Aswan University, Aswan, \\ Egypt; ${ }^{3}$ Community Medicine \\ Department, Assiut University, Assiut, \\ Egypt
}

Introduction: Percutaneous coronary intervention (PCI) has improved recanalization of infarct-related arteries (IRA); however, TIMI-III flow does not always mean an efficient myocardial reperfusion. Myocardial blush grade $(\mathrm{MBG})$ is used as a predictor for coronary microvascular obstruction. We assessed the association between ankle-brachial index (ABI), a widely used method for diagnosis of peripheral arterial disease (PAD), and coronary microvascular obstruction (MVO) as detected by MBG after primary PCI.

Patients and Methods: The study included 335 patients with ST-elevation myocardial infarction who had primary PCI. History taking, clinical examination, laboratory assessment, ECG and Echocardiography were done for every participant. MBG was assessed for patients after PCI procedure. ABI for all participating patients was calculated.

Results: Two hundred and sixty-one patients fulfilled the inclusion criteria with mean age $58.8 \pm 10.7$ years, $84 \%$ were males. Sixty-one percent had anterior wall myocardial infarction. After primary PCI, despite achieving TIMI flow III in all study patients, only $37 \%$ had normal MBG. There was a statistically significant relationship between MBG and site of infarction, left ventricular ejection fraction and ABI. Low ABI was found to predict poor MBG.

Conclusion: Coronary artery disease (CAD) is well linked to PAD. MBG can be used to assess coronary MVO after primary PCI. Poor MBG is associated with low ABI. This could establish a relationship between PAD and coronary MVO after primary PCI.

Keywords: microvascular coronary obstruction, peripheral arterial disease, myocardial blush grade, ankle-brachial index

\section{Background}

PCI has increased the rate of effective recanalization of IRAs to $>90 \%$. Reperfusion therapy for acute myocardial infarction (AMI) is proposed to be angiographically accepted when TIMI III flow is achieved in the IRA. ${ }^{1,2}$

However, even TIMI Grade III flow in the epicardial artery does not always mean an efficient myocardial reperfusion. ${ }^{3-6}$ Some patients have unsatisfactory reperfusion at the level of myocardial tissue. Many mechanisms have been suggested to be causative as, no reflow ${ }^{7}$ and distal embolization. ${ }^{8-10}$ Therefore, other predictors related to epicardial reperfusion as well as myocardial reperfusion are mandatory. $\mathrm{MBG}$ is developed as an angiographic surrogate of myocardial perfusion. ${ }^{11} \mathrm{MBG}$ as a predictor for coronary microvascular obstruction remains controversial. Porto et al found a definite inverse stepwise relation between
Correspondence: Ahmed Abdel-Galee Cardiovascular Medicine Department, Assiut University Heart Hospital, Assiut University, Assiut 71526, Egypt

Tel +2 01005015156

Email ahmed.galeel@aun.edu.eg
Vascular Health and Risk Management 2021:17 23-32 
microvascular obstruction (MVO) scores and MBGs. ${ }^{12}$ Angiographic evaluation of the microcirculation using myocardial blush scores correlates with other accurate methods of assessing myocardial perfusion like magnetic resonance imaging. It enables the instant assessment of microvascular patency in the catheterization laboratory. ${ }^{12}$

The ABI, defined as the ratio of ankle and brachial systolic blood pressure ${ }^{13}$ is a widely accepted method for the diagnosis of PAD. ${ }^{14}$ Moreover, the ABI is a parameter of diffuse atherosclerosis. ${ }^{15}$ The American Heart Association recommends that the value of $\mathrm{ABI} \leq 0.90$ defines PAD. ${ }^{16}$ The existence of PAD in patients with CAD remarkably increases the risk of cardiovascular (CV) morbidity and mortality. ${ }^{17}$ So, the ABI may improve risk stratification in patients with CAD. Though the relationship between PAD and CAD is well established, yet no consistent firm relationship between PAD and microvascular coronary obstruction in patients suffering AMI could be detected.

\section{Aim of the Study}

To assess the relationship between $\mathrm{ABI}$ and $\mathrm{MBG}$ among patients who undergo primary PCI.

\section{Patients and Methods}

\section{Patients}

The study is a cross-sectional prospective analytic study. It was conducted in Cardiology Department, Assiut University Heart Hospital. Informed written consent was taken from every participant and the study was approved by the local Ethical Committee, Faculty of Medicine, Aswan University, under the number (306/11/18, Faculty of Medicine, Aswan University, Aswan, EGYPT). The research was conducted in accordance with the Declaration of Helsinki.

The study included 335 patients with the diagnosis of STEMI who were admitted to Assiut University Heart Hospital and eligible for primary PCI. The diagnosis of STEMI was based on the fourth universal definition of myocardial infarction. ${ }^{18}$

Exclusion criteria include previous coronary revascularization such as PCI or coronary artery bypass graft (CABG) surgery, advanced heart failure and/or pulmonary oedema, known previous renal impairment, known PAD and/or previous peripheral revascularization or limb amputation. Also, patients who would not achieve TIMI III flow within the culprit vessel or those with more than $30 \%$ residual stenosis at the occluded site by the end of the procedure were excluded.

\section{Methodology}

Each participant was subjected to the followings:

(a) Careful history taking including gender, age, special habits mainly smoking was reported. Full clinical examination, focusing on patients' haemodynamics including blood pressure and heart rate, was done.

(b) Electrocardiography: Standard 12-lead ECGs were recorded before PCI.

(c) Transthoracic Echocardiography: Routine echocardiography was performed after primary PCI within 24 hours. $^{19}$

(d) Laboratory tests including assessment of serum creatinine, haemoglobin and troponin I.

(e) Angiographic procedure: All the study populations were pretreated with loading ticagrelor $180 \mathrm{mg}$ on admission. Coronary angiography and PCI were performed following the femoral or radial approaches as appropriate. The antegrade flow rate was assessed before and at the end of primary PCI according to TIMI trial classification. ${ }^{7}$ All angiograms were acquired with a frame rate of 15 frames/sec.

\section{MBG Assessment}

From multiple projections, a single view would be selected that best display the myocardial infarct area of interest. MBG was reported by a blinded experienced interventional cardiologist. It was assessed on the final angiogram after PCI, based on the visual assessment of contrast opacification of the myocardial territory supplied by the infarct vessel. ${ }^{20} \mathrm{MBG}$ was graded as 0 when no blush or contrast opacification could be detected. It was assigned as I in those with minimal blush or contrast opacification, II when moderate blush or contrast opacification but less than that of a non-IRA and III in those normal blush or contrast opacification compared with that of a non-IRA. ${ }^{20}$

\section{$\mathrm{ABI}$ Measurement}

After resting the patient in the supine position for at least 10 minutes, ABI measurement was carried out. ${ }^{16}$

\section{Statistical Analysis}

Data were expressed as mean value $\pm \mathrm{SD}$ or as median value with interquartile range. Differences in continuous variables were evaluated with Student's $t$-test for normally distributed continuous variables, Mann-Whitney $U$-test for 


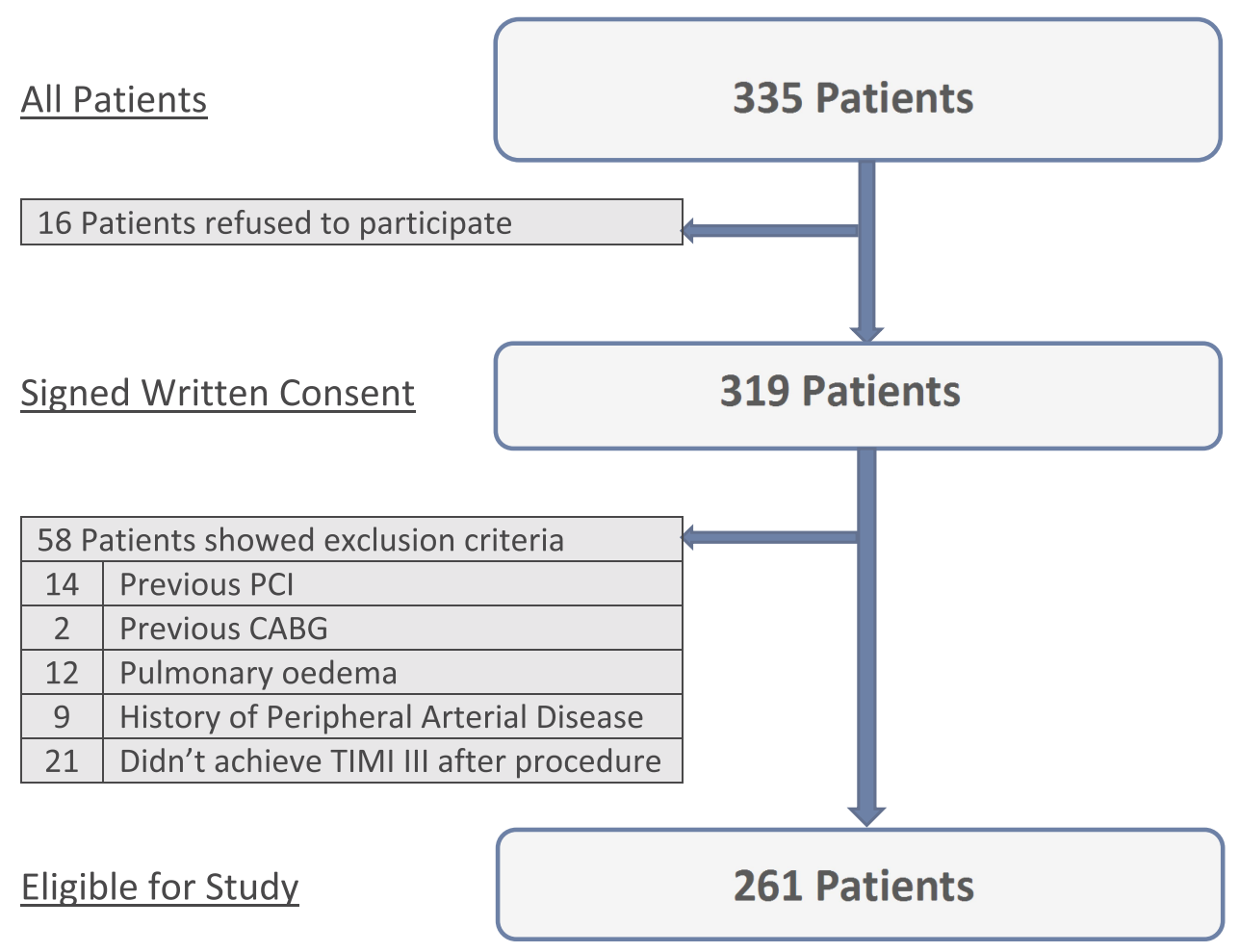

Figure I Flowchart of the study population.

non-parametrically distributed continuous variables and chi-square tests for categorical variables. The clinical and demographic factors with proven statistical significance from the univariate analyses were further included in multivariate logistic regression models to investigate the significant factors influencing MBG (Odds Ratio -OR, 95\% confidence interval $-95 \%$ CI- and p-value). Statistical analyses were done with SPSS version 20 software. A p-value of $<0.05$ was considered statistically significant.

\section{Results}

A total of 335 patients diagnosed with STEMI and eligible for primary PCI were recruited. Finally, 261 patients were enrolled in the study. Figure 1 shows the flowchart of the study population.

\section{Sociodemographic, Clinical,} Electrocardiographic, Echocardiographic, Laboratory, $\mathrm{ABI}$ and Angiographic Characteristics of Our Study Population

The mean age of the study population was 58.8 years old with an age range of 24-91 years old. Nearly three quarters of them were males. Only eight patients $(3.1 \%)$ were actually on clopidogrel. More than half of the studied population had anterior wall myocardial infarction. On coronary angiography, about $10 \%$ (26 patients) of the studied population had spontaneous lysis within the IRA resulting in TIMI-I flow prior to the procedure. Intracoronary thrombus was detected in about one quarter of the population (62 patients, $23.8 \%$ ), for which thrombectomy was not performed (Table 1).

\section{Determinants of MBG}

We divided the study population into three groups according to the MBG.

(1) Group I: It included 41 patients (15.7\%) with minimal blush (MBG-I).

(2) Group II: It included 121 patients (46.4\%) with moderate blush (MBG-II).

(3) Group III: It included 99 patients (37.9\%) with normal blush (MBG-III).

There was statistically significant difference between the three groups regarding history of hypertension ( $p$ value 0.049 ), site of myocardial infarction ( $\mathrm{p}$ value 0.006 ), left ventricular ejection fraction ( $p$ value $<0.001$ ), ABI ( $p$ value $<0.001$ ), serum troponin level ( $p$ value $<0.001$ ) and the occluded culprit vessel ( $p$ value 0.004). Table 2 shows the sociodemographic, clinical, ABI, electrocardiographic, laboratory, echocardiographic and angiographic characteristics of the three groups. 
Table I Sociodemographic, Clinical, Electrocardiographic, Echocardiographic, Laboratory, $\mathrm{ABI}$ and Angiographic Characteristics of Our Study Population

\begin{tabular}{|c|c|}
\hline Parameters & $n=26 I$ \\
\hline Age $($ mean $\pm S D)$ in years & $58.79 \pm 10.7$ \\
\hline Sex, male (\%) & $219(83.9)$ \\
\hline Smoking (\%) & $156(59.8)$ \\
\hline Diabetes mellitus (\%) & $71(27.2)$ \\
\hline Hypertension (\%) & $85(32.6)$ \\
\hline Ischaemic heart disease (\%) & $33(12.6)$ \\
\hline Clopidogrel pretreatment (\%) & $8(3.1)$ \\
\hline Systolic blood pressure in $\mathrm{mmHg}($ mean $\pm \mathrm{SD})$ & $112.49 \pm 17.27$ \\
\hline Diastolic blood pressure in $\mathrm{mmHg}($ mean $\pm \mathrm{SD})$ & $73.33 \pm 11.82$ \\
\hline Heart rate in beats/min (mean $\pm S D)$ & $81.98 \pm 12.69$ \\
\hline \multicolumn{2}{|l|}{ Site of infarction } \\
\hline - Anterior (\%) & $161(61.6)$ \\
\hline - Inferior (\%) & $55(21.1)$ \\
\hline - Inferoposterior (\%) & $43(16.5)$ \\
\hline - Lateral (\%) & $2(0.8)$ \\
\hline Ejection fraction (mean $\pm S D)$ & $50.64 \pm 8.9$ \\
\hline Serum Troponin I in ng/mL (mean \pm SD) & $3.46 \pm 1.2$ \\
\hline Serum creatinine in $\mathrm{mg} / \mathrm{dL}($ mean $\pm \mathrm{SD})$ & $1.09 \pm 0.23$ \\
\hline Hemoglobin level in $\mathrm{mg} / \mathrm{dL}($ mean $\pm \mathrm{SD})$ & $12.44 \pm 1.6$ \\
\hline $\mathrm{ABI}($ mean $\pm S D)$ & $0.93 \pm 0.06$ \\
\hline \multicolumn{2}{|l|}{ Culprit vessel } \\
\hline - LAD (\%) & $162(62.1)$ \\
\hline - $\operatorname{LCX}(\%)$ & $31(11.8)$ \\
\hline - RCA (\%) & $67(25.7)$ \\
\hline - Ramus (\%) & $\mathrm{I}(0.4)$ \\
\hline Presence of total occlusion in culprit vessel (\%) & $235(90)$ \\
\hline Presence of coronary thrombus (\%) & $62(23.8)$ \\
\hline Number of affected vessels (mean $\pm S D$ ) & $1.94 \pm 0.77$ \\
\hline - One (\%) & $83(31.8)$ \\
\hline - Two (\%) & $113(43.3)$ \\
\hline - Three or more (\%) & $65(24.9)$ \\
\hline Number of stents: mean $\pm S D$ & $\mathrm{I} .1 \pm 0.38$ \\
\hline - One (\%) & $236(90.4)$ \\
\hline - Two (\%) & $20(7.7)$ \\
\hline - Three (\%) & $5(1.9)$ \\
\hline Balloon pre-dilatation (\%) & $246(94.3)$ \\
\hline
\end{tabular}

(Continued)
Table I (Continued).

\begin{tabular}{|l|l|}
\hline Parameters & $\mathbf{n = 2 6 I}$ \\
\hline MBG: & $41(15.7)$ \\
\hline Grade I (\%) & $121(46.4)$ \\
Grade II (\%) & $99(37.9)$ \\
Grade III (\%)
\end{tabular}

Abbreviations: $A B I$, ankle-brachial index; $L A D$, left anterior descending artery; LCX, left circumflex artery; RCA, right coronary artery; MBG, myocardial blush grade.

\section{Predictors of Poor MBG}

Table 3 shows the multivariate regression analysis of independent correlates of myocardial blush. After adjusting for age and gender, the final logistic regression model contained four predictors: history of hypertension, $\mathrm{ABI}<0.9$, high serum troponin I and low left ventricular ejection fraction (EF).

In other words, patients with a history of hypertension were 2.4 times more likely to have abnormal MBG after primary PCI (AOR=2.46, 95\% CI: 1.180-5.104, p value 0.016). Also, patients with $\mathrm{ABI}<0.9$ were 6.4 times more likely to have abnormal $\mathrm{MBG}$ ( $\mathrm{AOR}=6.43,95 \% \mathrm{CI}$ : 3.$162-13.078$, $\mathrm{p}$ value $<0.001)$. Conversely, with a one percentage increase in the ejection fraction, there was an $11 \%$ decrease in the probability of having abnormal blush among cases $(\mathrm{AOR}=0.89$, 95\% CI: 0.857-0.928, $\mathrm{p}$ value $<0.001)$. With the increase in serum troponin I on admission, there was an increase in the likelihood of having abnormal $\mathrm{MBG}$ after primary $\mathrm{PCI}(\mathrm{AOR}=1.48,95 \% \mathrm{CI}$ : $1.135-1.932$, $\mathrm{p}$ value 0.004$)$.

\section{Diagnostic Performance for $A B I$ to Predict Coronary Microvascular Obstruction}

We used ROC curve statistics in order to set up a point of ABI beyond which we can reliably predict poor MBG. Using a cut-off of 0.9 , the accuracy, sensitivity and specificity to predict minimal/moderate blush was $79.5 \%, 87 \%$ and $72 \%$, respectively, (AUC $=0.733$; 95\% CI: $0.671-$ $0.794, \mathrm{p}<0.001$ ) with standard error of 0.03 , Figure 2 .

\section{Discussion}

Primary PCI implies rapid balloon angioplasty, may be with stenting, without prior administration of fibrinolytic therapy or platelet glycoprotein IIb/IIIa inhibitors, to open the IRA. ${ }^{21}$ TIMI Grade III flow in the epicardial 
Table 2 The Sociodemographic, Clinical, ABI, Electrocardiographic and Echocardiographic, Laboratory and Angiographic Characteristics of the Three Groups

\begin{tabular}{|c|c|c|c|c|}
\hline Parameters & Group I $(n=4 I)$ & Group II $(n=121)$ & Group III (n = 99) & $P$ value \\
\hline Age $($ mean $\pm S D)$ in years & $60.1 \pm 12.0$ & $58.6 \pm 10.5$ & $58.6 \pm 10.3$ & 0.697 \\
\hline Sex, male (\%) & 35 (85.4\%) & $104(86 \%)$ & $80(80.8 \%)$ & 0.377 \\
\hline Smoking (\%) & $24(58.5 \%)$ & $75(62 \%)$ & $57(57.6 \%)$ & 0.763 \\
\hline Diabetes mellitus (\%) & II (26.8\%) & $34(28.1 \%)$ & $26(26.3 \%)$ & 0.877 \\
\hline Hypertension (\%) & $16(39 \%)$ & $4 \mathrm{l}(33.9 \%)$ & $28(28.3 \%)$ & 0.049 \\
\hline Ischaemic heart disease (\%) & $5(12.2 \%)$ & $16(13.2 \%)$ & $12(12.1 \%)$ & 0.929 \\
\hline Clopidogrel pretreatment (\%) & I (2.4) & $6(5)$ & $\mathrm{I}(\mathrm{I})$ & 0.232 \\
\hline Systolic blood pressure (mean $\pm \mathrm{SD})$ in $\mathrm{mmHg}$ & $112.88 \pm 21.1$ & $111.72 \pm 15.3$ & $113.27 \pm 17.9$ & 0.794 \\
\hline Diastolic blood pressure (mean $\pm \mathrm{SD})$ in $\mathrm{mmHg}$ & $75.38 \pm 14.54$ & $72.23 \pm 10.62$ & $73.85 \pm 11.97$ & 0.297 \\
\hline Heart rate in beats/min (mean $\pm S D)$ & $80.95 \pm 10.68$ & $82.11 \pm 12.83$ & $82.23 \pm 13.36$ & 0.856 \\
\hline \multicolumn{4}{|l|}{ Site of infarction } & \multirow[t]{3}{*}{0.006} \\
\hline - Anterior (\%) & $29(70.8 \%)$ & $83(68.6 \%)$ & $49(49.5 \%)$ & \\
\hline - Non-Anterior ${ }^{+}(\%)$ & $12(29.2 \%)$ & $38(31.4 \%)$ & $50(50.5 \%)$ & \\
\hline Ejection fraction (mean $\pm S D$ ) & $45.76 \pm 7.7$ & $49.14 \pm 8.2$ & $54.48 \pm 8.9$ & $<0.001$ \\
\hline $\mathrm{ABI}($ mean $\pm \mathrm{SD})$ & $0.89 \pm 0.06$ & $0.91 \pm 0.05$ & $0.96 \pm 0.05$ & $<0.001$ \\
\hline Serum Troponin I in $\mathrm{ng} / \mathrm{mL}$ (mean $\pm S D$ ) & $3.89 \pm 1.3$ & $3.61 \pm 1.2$ & $3.10 \pm 1.1$ & $<0.001$ \\
\hline Serum creatinine in $\mathrm{mg} / \mathrm{dL}$ (mean $\pm \mathrm{SD}$ ) & $1.12 \pm 0.3$ & $1.07 \pm 0.2$ & $1.10 \pm 0.2$ & 0.441 \\
\hline Hemoglobin level in $\mathrm{mg} / \mathrm{dL}($ mean $\pm S D)$ & $12.62 \pm 1.6$ & $12.24 \pm 1.5$ & $12.61 \pm 1.7$ & 0.176 \\
\hline \multicolumn{4}{|l|}{ Culprit vessel } & \multirow[t]{3}{*}{0.004} \\
\hline - LAD (\%) & $30(73.1 \%)$ & $83(68.6 \%)$ & 49 (49.5\%) & \\
\hline - Non-LAD* (\%) & II (26.9\%) & $38(31.4 \%)$ & $50(50.5 \%)$ & \\
\hline Presence of total occlusion (\%) & $34(82.9)$ & $112(92.6)$ & 89 (89.9) & 0.205 \\
\hline Presence of coronary thrombus (\%) & $8(19.5)$ & $31(25.6)$ & $23(23.2)$ & 0.721 \\
\hline \multicolumn{4}{|l|}{ Number of affected vessels } & \multirow[t]{4}{*}{0.388} \\
\hline - One (\%) & $12(29.3 \%)$ & $44(36.4 \%)$ & 27 (27.3\%) & \\
\hline - More than one (\%) & $29(70.7)$ & 77 (63.6\%) & $72(72.7 \%)$ & \\
\hline - Mean $\pm S D$ & $1.95 \pm 0.74$ & $1.88 \pm 0.78$ & $2.01 \pm 0.76$ & \\
\hline \multicolumn{4}{|l|}{ Number of stents } & \multirow[t]{4}{*}{0.300} \\
\hline - One (\%) & 39 (95.l\%) & 109 (90.1\%) & $88(88.9 \%)$ & \\
\hline - More than one $(\%)$ & $2(4.9 \%)$ & 12 (9.9\%) & II (II.I\%) & \\
\hline - Mean $\pm S D$ & $1.05 \pm 0.22$ & $1.12 \pm 0.37$ & $1.14 \pm 0.43$ & \\
\hline Balloon pre-dilatation (\%) & $41(100 \%)$ & $113(93.4 \%)$ & 92 (92.9\%) & 0.163 \\
\hline
\end{tabular}

Notes: Bold text indicates statistical significance; ${ }^{+}$Non-Anterior indicates inferior, inferoposterior and lateral wall myocardial infarctions; *Non-LAD indicates LCX, Ramus and RCA.

Abbreviation: $A B I$, ankle-brachial index. 
Table 3 Logistic Regression Model for the Predictors of Poor MBG

\begin{tabular}{|c|c|c|}
\hline Factors & OR $(95 \% \mathrm{CI})$ & P value \\
\hline Age & $1.008(0.978-1.038)$ & 0.614 \\
\hline Sex (male) & $1.425(0.580-3.503)$ & 0.440 \\
\hline Hypertension & $2.455(1.180-5.104)$ & 0.016 \\
\hline $\mathrm{ABI}<0.9$ & $6.430(3.162-13.078)$ & $<0.001$ \\
\hline Serum troponin level $(\mathrm{ng} / \mathrm{mL})$ & $1.481(1.135-1.932)$ & 0.004 \\
\hline Ejection fraction & $0.892(0.857-0.928)$ & $<0.001$ \\
\hline
\end{tabular}

Abbreviation: $A B I$, ankle-brachial index.

artery does not always result in actual myocardial reperfusion $^{3-6}$ and salvage. ${ }^{22}$ Microvascular compromise can be present in $10 \%$ to $15 \%$ of all patients who undergo successful primary PCI procedures. $^{23}$ Satisfactory myocardial perfusion after primary PCI is associated with better clinical outcomes ${ }^{24}$ whereas impaired coronary circulation is associated with suboptimal myocardial perfusion, large infarct size, and increased mortality rates. $^{25}$
Angiographic methods for assessing reperfusion in the cath lab, based on the kinetics of dye penetration within the myocardium (myocardial "blush"), have been evolved. 3,4

MBG is used as an angiographic estimate of myocardial perfusion. ${ }^{11}$ Evaluation of coronary microcirculation using myocardial blush scores correlates well with some accurate methods for assessing myocardial perfusion such as magnetic resonance imaging and enables an instant evaluation of microvascular patency in the cath lab. ${ }^{12} \mathrm{MBG}$ has been used to test new therapeutic strategies aiming to lessen myocardial reperfusion injury. ${ }^{26}$ It indirectly assesses MVO, which is a strong predictor of adverse outcome in patients after $\mathrm{AMI}^{7,27}$ and occurs in up to one third of patients after an angiographically accepted recanalization of the IRA. ${ }^{28}$ Therefore, MBG may be suitable for evaluating microvascular function in the cath lab during PCI. ${ }^{29}$ Porto et al found a linear correlation between poor $\mathrm{MBG}$ and cardiac magnetic resonance (CMR) signs of vascular obstruction. This confirms the relationship between post-PCI MBG and CMR signs of microvascular obstruction. ${ }^{12}$

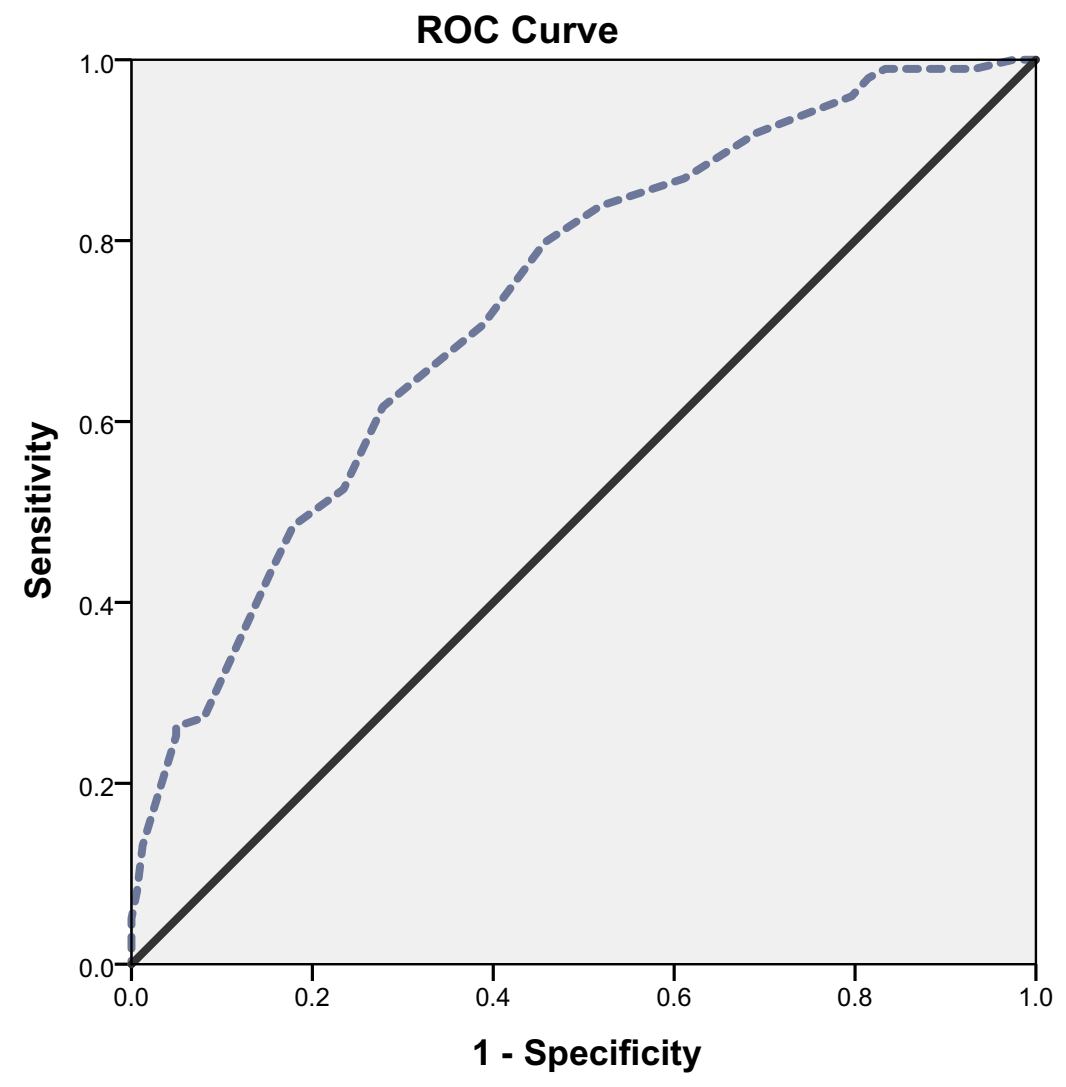

Diagonal segments are produced by ties.

Figure 2 ROC curve for $A B I$ to predict poor MBG. 
In our study, only three categories for MBG were represented as MBG 1, 2, and 3 stated as minimal, moderate and normal blushes, respectively. No one was detected with MBG 0 . In other studies, there were patients labelled as MBG 0 , where no blush was detected. ${ }^{5,27,30}$ In these studies, where MBG 0 was represented, they included all patients who had PCI regardless of their post-procedural TIMI flow, ${ }^{5,6}$ in contrast to ours where we included only patients with TIMI flow III. This is like the study of Porto et al, who studied 27 patients who had successful PCI with TIMI III flow after the procedure. They found MBG 0 in only two patients of their study cohort. ${ }^{12}$ Also, Vicenti et al reported MBG 0 only in two patients out of 39 patients who had TIMI III flow post-PCI. ${ }^{31}$ Moreover, some authors divided their study population into three categories combining MBG 0 and 1 into the same category and represented as minimal or no opacification of the myocardium in the distribution of the occluded artery. ${ }^{12}$

Our study reported MBG as normal in about 38\%, $46.5 \%$ showed moderate blush and about $16 \%$ had minimal blush. Obviously, only one third of our study population who had a satisfactory post-procedural TIMI-III flow, had normal myocardial blush indicating that in two thirds of our population, there is still some MVO. Residual MVO has a crucial role in prognosis and its presence is linked to suboptimal myocardial perfusion, increased infarct size, and higher mortality rates. ${ }^{25}$

The study reported no relationship between MBG and age, sex, smoking habit, DM and previous IHD. This goes with what has been published in some studies. ${ }^{5,30,32}$ In contrast to what had been reported by Tarantini et al who stated that poor myocardial blush grade was associated with old age, hypertensives and diabetics. Paradoxically their study reported a good MBG in current smokers. ${ }^{33}$

The study also reported a statistically significant relationship between MBG and ejection fraction. This has been previously reported. ${ }^{31,32}$ Tarantini et al studied patients with cardiogenic shock who had primary PCI, they reported no statistically significant difference between those with postprocedural acceptable MBG and those with poor MBG regarding left ventricular function; however, the mean EF in both study groups was impaired ( $33 \%$ versus $38 \%)^{33}$

The current study reported that inferior wall myocardial infarction was associated with better MBG. This is mostly attributed to small infarct size. Many studies have proved that the infarct size is related to MBG. Vicenti et al stated that increased infarct size, measured by cardiac MRI, is associated with increased liability for MVO, hence poor myocardial perfusion and low MBG. ${ }^{31}$ This also was confirmed by Porto et al who stated that MBG is directly related to MVO and infarction size. They showed that after primary or rescue PCI, MBG is inversely and linearly related to the extent of perfusion defects assessed using early CMR. ${ }^{12}$ On the other hand, Tarantini et al found no statistically significant relationship between MBG and site of infarction. ${ }^{33}$

Consequently, the culprit artery played role in determining MBG. Patients with LAD lesion had the worst MBG in comparison to those who had LCX and/or RCA lesions. This was also reported by Marra et al who studied 320 patients with acute STEMI who had primary PCI. They reported that in patients with no or minimal MBG, the left anterior descending coronary artery was the most frequently involved IRA. ${ }^{32}$ Stone et al studied 173 high-risk patients with AMI who had primary PCI. They found that patients with LAD occlusion had worse post-procedure MBG than those who had other vessels' occlusion. They stated that the powerful predictors of poor MBG were the inability to achieve TIMI-III flow and intervention in the LAD territory. ${ }^{5}$

The reason that LAD intervention results in suboptimal myocardial perfusion compared to intervention in other vessels is not clear. Many factors could be claimed such as high thrombus burden, plenty of active vasohumoral responses, augmented myocardial oedema and necrosis in LAD infarction. ${ }^{7,34,35}$ It is interesting to attribute the greater mortality of patients with anterior myocardial infarction compared with non-anterior myocardial infarction, not only to the increased muscle mass at risk ${ }^{36}$ but also to a lower propensity of achieving normal MBG despite restored epicardial flow. On the other hand, Fernandes et al found no influence of the IRA with postprocedural myocardial perfusion. ${ }^{30}$

The association between PAD and CAD significantly increases the risk of $\mathrm{CV}$ events and death. ${ }^{17}$ So, assessment of $\mathrm{ABI}$ may improve risk stratification in patients with CAD. A well-designed meta-analysis published in 2015 stated that low $\mathrm{ABI}(<0.9)$ was an independent predictor of cardiovascular or all-cause mortality in the general population. ${ }^{37}$

Our study reported that about one third of our patients' population who underwent primary PCI for an acute coronary insult had abnormal ABI. This is comparable to what had been reported by other studies. The prevalence of abnormal ABI among CAD patients ranges from $15 \%$ to $40 \%{ }^{38,39}$

Despite that many previous studies linked between abnormal ABI and the extent of coronary atherosclerosis; our study failed to show such a relationship. Abul-Hasnat et al reported that abnormal $\mathrm{ABI}$ is a strong independent predictor for 
severity of CAD as assessed by Gensini score. ${ }^{40}$ In a study carried out on 273 patients with PAD and angiographically documented coronary artery lesions, there was a strong negative correlation between ABI and the severity of CAD. Among those patients with $\mathrm{ABI}$ less than 0.4, there was extensive CAD as evident by three or more significant lesions in more than $80 \%$ of them. ${ }^{41}$ However, the studied population was elderly (mean age 71 years old) in contrast to ours (mean age 58 years old). One of the limitations of our study is that we did not assess the severity of coronary tree affection using a valid scoring system such as SYNTAX score rather than defining our study population into single, two- or multi-vessel disease. This could hinder the proper assessment of the relationship between the extent of CAD and ABI among our study population.

One of the independent correlates of ABI is MBG. This is evident either by univariate analysis or multivariable logistic regression. To our knowledge, our study is the first to demonstrate a relationship between $\mathrm{ABI}$ and MVO as assessed by MBG. The link between PAD, as detected by $\mathrm{ABI}$, and $\mathrm{CAD}$ is well established. ${ }^{42}$ Moreover, the association between low $\mathrm{ABI}$ and poor MBG could be explained by the presence of microvascular dysfunction. There is a strong association between coronary microvascular dysfunction and $\mathrm{MBG}$ after primary PCI. $^{3}$ Simultaneously, ABI is shown to be significantly low in patients with microvascular dysfunction in patients with diabetes mellitus. ${ }^{43}$ Our results associated abnormal ABI and coronary MVO in critically managed patients undergoing primary PCI. Such association could help to predict those patients who would mostly get better after primary PCI. Also, to detect those patients who would not get benefit and may get worse after the procedure due to coronary MVO in spite of having TIMI III flow after the procedure. Such patients' category should not be overlooked and should draw more attention as many of them continue to have symptoms, so other lines of pharmacotherapeutic treatment could add further benefits.

\section{Limitations}

We relied upon MBG assessment which is less sensitive and specific than CMR imaging. It would be better to have CMR for all our study population. However, our population consisted of those who are suffering from AMI, many of them were in a critical status, so it was not practically feasible to do CMR for such a population. Moreover, some previous studies stated that $\mathrm{MBG}$ is well correlated to CMR findings.

\section{Conclusion}

The study confirmed the intimate relationship between CAD and PAD. Moreover, this relationship could be extended to the level of coronary microvascular bed. Determinants of poor MBG were hypertension, low ejection fraction, high serum troponin and low ABI.

\section{Abbreviations}

PCI, percutaneous coronary intervention; MBG, myocardial blush grade; ABI, ankle-brachial index; PAD, peripheral arterial disease; STEMI, ST-elevation myocardial infarction; IRA, infarct related artery; CAD, coronary artery disease; AMI, acute myocardial infarction; MVO, microvascular obstruction; $\mathrm{CV}$, cardiovascular; $\mathrm{CABG}$, coronary artery bypass graft; AOR, adjusted odds ratio; $\mathrm{CI}$, confidence interval; $\mathrm{EF}$, ejection fraction; ROC, receiver operating characteristics; AUC, area under the curve; CMR, cardiac magnetic resonance.

\section{Disclosure}

The authors report no conflicts of interest in this work.

\section{References}

1. Smith SC, Dove JT, Jacobs AK, et al. ACC/AHA guidelines for percutaneous coronary intervention (revision of the 1993 PTCA guidelines)-executive summary: a report of the American College of Cardiology/American Heart Association task force on practice guidelines (Committee to revise the 1993 guidelines for percutaneous transluminal coronary angioplasty) endorsed by the Society for Cardiac Angiography and Interventions. Circulation. 2001;103 (24):3019-3041. doi:10.1161/01.cir.103.24.3019

2. Fukushima N, Tsurumi Y, Jujo K, et al. Impact of myocardial reperfusion status on QT dispersion after successful recanalization of the infarct-related artery in acute myocardial infarction impact of myocardial reperfusion status on QT dispersion after successful recanalization of the infarct-related artery in acute myocardial infarction. $J$ Interv Cardiol. 2014;27(3):252-259. doi:10.1111/joic.12093

3. van 'T Hof AW, Liem A, Suryapranata H, Hoorntje JC, de Boer MJ, Zijlstra F. Angiographic assessment of myocardial reperfusion in patients treated with primary angioplasty for acute myocardial infarction: myocardial blush grade. Zwolle Myocardial Infarction Study Group. Circulation. 1998;97:2302-2306. doi:10.1161/01.CIR.97.23.2302

4. Gibson CM, Cannon CP, Murphy SA, et al. Relationship of TIMI myocardial perfusion grade to mortality after administration of thrombolytic drugs. Circulation. 2000;101:125-130. doi:10.1161/01. CIR.101.2.125

5. Stone GW, Peterson MA, Lansky AJ, Dangas G, Mehran R, Leon MB. Impact of normalized myocardial perfusion after successful angioplasty in acute myocardial infarction. $J$ Am Coll Cardiol. 2002;39:591-597. doi:10.1016/S0735-1097(01)01779-X

6. Gibson CM, Schomig A. Coronary and myocardial angiography: angiographic assessment of both epicardial and myocardial perfusion. Circulation. 2004;109:3096-3105. doi:10.1161/01.CIR.000013427 8.50359.CB

7. Ito H, Maruyama A, Iwakura K, et al. Clinical implications of the "no reflow" phenomenon: a predictor of complications and left ventricular remodelling in reperfused anterior wall myocardial infarction. Circulation. 1996;93:223-228. doi:10.1161/01.CIR.93.2.223 
8. Topol EJ, Yadav JS. Recognition of the importance of embolization in atherosclerotic vascular disease. Circulation. 2000;101:570-580. doi:10.1161/01.CIR.101.5.570

9. Yamada DM, Topol EJ. Importance of microembolization and inflammation in atherosclerotic heart disease. Am Heart J. 2000;140:S90S102. doi:10.1067/mhj.2000.111611

10. Henriques JP, Zijlstra F, Ottervanger JP, et al. Incidence and clinical significance of distal embolization during primary angioplasty for acute myocardial infarction. Eur Heart J. 2002;23:1112-1117. doi:10.1053/euhj.2001.3035

11. Henriques JP, Zijlstra F, Van't Hof AW, et al. Angiographic assessment of reperfusion in acute myocardial infarction by myocardial blush grade. Circulation. 2003;107:2115-2119. doi:10.1161/01. CIR.0000065221.06430.ED

12. Porto I, Burzotta F, Brancati M, et al. Relation of myocardial blush grade to microvascular perfusion and myocardial infarct size after primary or rescue percutaneous coronary intervention. Am J Cardiol. 2007;99:1671-1673. doi:10.1016/j.amjcard.2007.01.045

13. Al-Qaisi M, Nott DM, King DH, Kaddoura S. Ankle brachial pressure index (ABPI): an update for practitioners. Vasc Health Risk Manag. 2009;5:833-841. doi:10.2147/VHRM.S6759

14. D X, J L, Zou L, et al. Sensitivity and specificity of the ankle-brachial index to diagnose peripheral artery disease: a structured review. Vasc Med. 2010;15:361-369. doi:10.1177/1358863X10378376

15. Newman AB, Siscovick DS, Manolio TA, et al. Ankle-arm index as a marker of atherosclerosis in the cardiovascular health study. Cardiovascular heart study (CHS) collaborative research group. Circulation. 1993;88:837-845. doi:10.1161/01.CIR.88.3.837

16. Aboyans V, Criqui MH, Abraham P, et al. Measurement and interpretation of the ankle-brachial index: a scientific statement from the American Heart Association. Circulation. 2012;126:2890-2909. doi:10.1161/CIR.0b013e318276fbcb

17. Manfrini O, Amaduzzi PL, Cenko E, Bugiardini R. Prognostic implications of peripheral artery disease in coronary artery disease. Curr Opin Pharmacol. 2018;39:121-128. doi:10.1016/j.coph.2018.04.005

18. Thygesen K, Alpert JS, Jaffe AS, et al. Executive group on behalf of the Joint European Society of Cardiology (ESC)/American College of Cardiology (ACC)/American Heart Association (AHA)/World Heart Federation (WHF) task force for the universal definition of myocardial infarction. Circulation. 2018;138(20):e618-e651. doi:10.1161/ CIR.0000000000000617

19. Ibanez B, James S, Agewall S, et al. 2017 ESC guidelines for the management of acute myocardial infarction in patients presenting with ST-segment elevation: the task force for the management of acute myocardial infarction in patients presenting with ST-segment elevation of the European Society of Cardiology (ESC). Eur Heart J. 2018;39(2):119-177. doi:10.1093/eurheartj/ehx393

20. Karahan Z, Ucaman B, Ulug AV, et al. Effect of hematologic parameters on microvascular reperfusion in patients with ST-segment elevation myocardial infarction treated with primary percutaneous coronary intervention. Angiology. 2016;67(2):151-156. doi:10.1177/ 0003319715583204

21. Keeley EC, Hillis LD. Primary PCI for myocardial infarction with ST-segment elevation. $N$ Engl J Med. 2007;356:47-54. doi:10.1056/ NEJMct063503

22. Araszkiewicz A, Lesiak M, Grajek S, et al. Effect of microvascular reperfusion on prognosis and left ventricular function in anterior wall myocardial infarction treated with primary angioplasty. Int J Cardiol. 2007;114(2):183-187. doi:10.1016/j.ijcard.2006.01.057

23. Zalewski J, Zmudka K, Musialek P, et al. Detection of microvascular injury by evaluating epicardial blood flow in early reperfusion following primary angioplasty. Int J Cardiol. 2004;96(3):389-396. doi:10.1016/j.ijcard.2003.08.009
24. Gibson CM, Cannon CP, Murphy SA, et al. Relationship of the TIMI myocardial perfusion grades, flow grades, frame count, and percutaneous coronary intervention to long-term outcomes after thrombolytic administration in acute myocardial infarction. Circulation. 2002;105 (16):1909-1913. doi:10.1161/01.CIR.0000014683.52177.B5

25. Brosh D, Assali AR, Mager A, et al. Effect of no-reflow during primary percutaneous coronary intervention for acute myocardial infarction on six-month mortality. Am $J$ Cardiol. 2007;99 (4):442-445. doi:10.1016/j.amjcard.2006.08.054

26. Svilaas T, Vlaar PJ, van der Horst IC, et al. Thrombus aspiration during primary percutaneous coronary intervention. $N$ Engl J Med. 2008;358:557-567. doi:10.1056/NEJMoa0706416

27. Wu KC, Zerhouni EA, Judd RM, et al. Prognostic significance of microvascular obstruction by magnetic resonance imaging in patients with acute myocardial infarction. Circulation. 1998;97:765-772. doi:10.1161/01.CIR.97.8.765

28. Ito $\mathrm{H}$, Tomooka $\mathrm{T}$, Sakai $\mathrm{N}$, et al. Lack of myocardial perfusion immediately after successful thrombolysis. A predictor of poor recovery of left ventricular function in anterior myocardial infarction. Circulation. 1992;85:1699-1705. doi:10.1161/01.CIR.85.5.1699

29. Porto I, Hamilton-Craig C, Brancati M, Burzotta F, Galiuto L, Crea F. Angiographic assessment of microvascular perfusion-Myocardial blush in clinical practice. Am Heart J. 2010;160:1015-1022. doi:10.1016/j.ahj.2010.08.009

30. Fernandes MR, Fish RD, Canales J, et al. Restoration of microcirculatory patency after myocardial infarction results of current coronary interventional strategies and techniques. Tex Heart Inst J. 2012;39 (3):342-350.

31. Vicente J, Mewton N, Croisille P, et al. Comparison of the angiographic myocardial blush grade with delayed-enhanced cardiac magnetic resonance for the assessment of microvascular obstruction in acute myocardial infarctions. Catheter Cardiovasc Interv. 2009;74:1000-1007. doi:10.1002/ccd.22157

32. Marra MP, Corbetti F, Cacciavillani L, et al. Relationship between myocardial blush grades, staining, and severe microvascular damage after primary percutaneous coronary intervention: a study performed with contrast-enhanced magnetic resonance in a large consecutive series of patients. Am Heart J. 2010;159:1124-1132. doi:10.1016/j. ahj.2010.03.007

33. Tarantini G, Ramondo A, Napodano M, et al. Myocardial perfusion grade and survival after percutaneous transluminal coronary angioplasty in patients with cardiogenic shock. Am J Cardiol. 2004;93:1081-1085. doi:10.1016/j.amjcard.2004.01.031

34. Kloner RA, Ganote CE, Jennings RB. The "no reflow" phenomenon after temporary coronary occlusion in the dog. $J$ Clin Invest. 1974;54:1496-1508. doi:10.1172/JCI107898

35. Belli G, Pezzano A, De Biase AM, et al. Adjunctive thrombus aspiration and mechanical protection from distal embolization in primary percutaneous intervention for acute myocardial infarction. Catheter Cardiovasc Interv. 2000;50:362-370. doi:10.1002/1522726x(200007)50:3<362::aid-ccd22>3.0.co;2-h

36. Stone PF, Raabe DS, Jaffe AS. Prognostic significance of location and type of myocardial infarction: independent adverse outcome associated with anterior location. $J$ Am Coll Cardiol. 1988;11:453-463. doi:10.1016/0735-1097(88)91517-3

37. Qu B, Liu Q, Li J. Systematic review of association between low ankle-brachial index and all-cause cardiovascular, or non-cardiovascular mortality. Cell Biochem Biophys. 2015;73:571-575.

38. Lee JY, Lee SW, Lee WS, et al. Prevalence and clinical implications of newly revealed, asymptomatic abnormal ankle-brachial index in patients with significant coronary artery disease. JACC Cardiovasc Interv. 2013;6:1303-1313. doi:10.1016/j.jcin.2013.08.008 
39. Dieter RS, Tomasson J, Gudjonsson T, et al. Lower extremity peripheral arterial disease in hospitalized patients with coronary artery disease. Vasc Med. 2003;8:233-236. doi:10.1191/1358863x03vm506ra

40. Md Jafar A, Akanda MA, Khalequzzaman M, et al. Association of ankle-brachial index with the angiographic severity of patient with coronary artery disease. Cardiovasc J. 2018;10(2):201-205. doi:10.3329/cardio.v10i2.36293

41. Sukhija R, Aronow WS, Yalamanchili K, Peterson SJ, Frishman WH, Babu S. Association of ankle-brachial index with severity of angiographic coronary artery disease in patients with peripheral arterial disease and coronary artery disease. Cardiology. 2005;103:158-160. doi: $10.1159 / 000084586$
42. Sabedotti M, Sarmento-Leite R, Schaan de Quadros A. Anklebrachial index as a predictor of significant coronary artery disease in patients undergoing coronary angiography. Rev Bras Cardiol Invasiva. 2014;22(4):359-363. doi:10.1590/0104-1843000000060

43. Papanas N, Symeonidis G, Mavridis G, et al. Ankle-brachial index: a surrogate marker of microvascular complications in type 2 diabetes mellitus? Int Angiol. 2007;26(3):253-257.

\section{Publish your work in this journal}

Vascular Health and Risk Management is an international, peerreviewed journal of therapeutics and risk management, focusing on concise rapid reporting of clinical studies on the processes involved in the maintenance of vascular health; the monitoring, prevention and treatment of vascular disease and its sequelae; and the involvement of metabolic disorders, particularly diabetes. This journal is indexed on PubMed Central and MedLine. The manuscript management system is completely online and includes a very quick and fair peerreview system, which is all easy to use. Visit http://www.dovepress. com/testimonials.php to read real quotes from published authors. 